\title{
Smoking cessation programmes using traditional medicine in Korea
}

Soobin Jang ${ }^{1 \dagger}$, Yu Lee Park ${ }^{1 \dagger}$, Ju Ah Lee ${ }^{2}$, Kyeong Han Kim, Eun-Kyoung Lee ${ }^{1}$, Seung-Ho Sun ${ }^{3}$, Yong-Cheol Shin ${ }^{1}$, Seong-Gyu Ko ${ }^{1 *}$ and Sunju Park ${ }^{4^{*}}$ id

\begin{abstract}
Background: There are growing interests in using various methods including traditional and complementary medicines (T\&CM) for tobacco control. The study aimed to introduce how traditional Korean medicine (TKM) applied to smoking cessation programmes in Korea and to show the detail information of each programme for designing other smoke cessation programmes.
\end{abstract}

Methods: Reports of the smoke cessation programmes in Korea were searched on March 10th, 2016, from the webpages of the related agencies and the databases: the Ministry of Health and Welfare, the Korea Health Foundation, the Association of Korean Medicine, PubMed, Google scholar, the RISS, the KISS, the NDSL, and the OASIS. Smoking cessation programmes, projects, or services using traditional Korean medicine (TKM) were included with no language, implementation site, and year restrictions.

Results: The three smoking cessation programmes using TKM in South Korea were the public health centre smoking cessation programme (PHC-SCP), the Ministry of Gender Equality \& Family smoking cessation programme (MOGEF-SCP), and the National Health Insurance Service smoking cessation treatment project (NHIS-SCP). All programmes included ear acupuncture and counselling. Manual acupuncture was only used in the NHIS-SCP. The MOGEF-SCP and the NHIS-SCP used herbal medicines selectively. The PHC-SCP and MOGEF-SCP provided education programme and other tools such as non-smoking doll, self-writing handbook. They were run at no cost for participants. Treatment period were different for each programmes, 3 weeks, 4 weeks, 8 to 12 weeks, respectively. Treatment frequency was twice a week for PHC-SCP and MOGEF-SCP, and dependent on each clinic for NHIS-SCP.

Conclusions: This study showed the summaries of the smoking cessation programme that used TKM. The three programmes and the detail information will be a reference for other countries that are going to apply T\&CM to their smoking cessation programme. Though TKM integrated smoking cessation programmes had been contributed to stop smoking, persistent efforts are needed to develop more effective and various treatments. In addition, this study suggests that consistent support and systematic reporting system are needed to be successful in non-smoking strategy.

Keywords: Smoking cessation, Tobacco control, Traditional Korean medicine, Ear acupuncture

\footnotetext{
*Correspondence: epiko@khu.ac.kr; sjpark422@gmail.com

${ }^{\dagger}$ Equal contributors

${ }^{1}$ Department of Preventive Medicine, College of Korean Medicine, Kyung

Hee University, 26 Kyungheedae-ro, Dongdaemun-gu, Seoul 02447, Republic

of Korea

${ }^{4}$ Department of Preventive Medicine, College of Korean Medicine, Daejeon

University, 62 Daehak-ro, Daejeon 34520, Republic of Korea

Full list of author information is available at the end of the article
}

(c) The Author(s). 2016 Open Access This article is distributed under the terms of the Creative Commons Attribution 4.0 International License (http://creativecommons.org/licenses/by/4.0/), which permits unrestricted use, distribution, and reproduction in any medium, provided you give appropriate credit to the original author(s) and the source, provide a link to the Creative Commons license, and indicate if changes were made. The Creative Commons Public Domain Dedication waiver (http://creativecommons.org/publicdomain/zero/1.0/) applies to the data made available in this article, unless otherwise stated. 


\section{Background}

Smoking is one of the biggest causes of death, and it is related to the death of one in ten people (6 million) every year. Smoking related death is expected to increase to 8 million by 2030 if no proper smoking cessation policies are implemented [1]. According to the World Health Organization (WHO), $21 \%$ of the world populations above 15 years old were smokers in 2012 [2]. To solve the problem, the WHO developed the Framework Convention on Tobacco Control (FCTC) in 2003, which is the first international treaty on public health regarding the reduction of smoking related diseases and death. The diagnosis and treatment of tobacco-dependence is included in the public health systems of 81 countries, and 72 of these systems include insurance that covers the cost of drugs for tobacco-dependence [3].

The most popular treatments of tobacco control are nicotine replacement therapy (NRT), varenicline, bupropion, cytisine, clonidine, nortriptyline, and escitalopram $[4,5]$. Since most smokers are dependent on nicotine, it is difficult to be successful at smoking cessation through drug therapy alone [6]. Therefore, a comprehensive approaches including emotional support should be provided to smokers [7]. As adverse events from pharmaceuticals and NRT, such as sleep disorder, nausea, vomiting, and skin irritation, are reported, the development of a safer intervention is needed for smoking cessation $[4,5]$. The success rate of smoking cessation can be increased when multiple methods are combined, such as counselling, education, complementary therapy, and regulatory policy [6].

There has been a growing interest in traditional and complementary medicine (T\&CM) for smoking cessation treatment in many countries [8]. Traditional Korean medicine (TKM) is one of the T\&CM that have been widely used in Korea and it has been a role in smoking cessation treatment along with western medicines and NRT for decades within the national health system of South Korea. Also, there have been many clinical trials or experimental studies about smoking cessation with acupuncture $[9,10]$. In South Korea, tobacco control is included in the Health Plan 2020, and its goal is to reduce the smoking rate to $29 \%$ in men and to $6 \%$ in women by 2020 [11].

The objective of this study was to describe how TKM has been applied in smoking cessation programmes and how this can be expanded and used to improve other smoking cessation programmes that will increase smoke cessation rates. This study is the first research result of our STOP (Stop Tobacco Programme using TKM) study series.

\section{Methods}

\section{Search strategy}

Official reports about public health programmes were searched from the webpages of the government and related bodies: the Ministry of Health and Welfare
(MW, www.mohw.go.kr), the Korea Health Foundation (www.khealth.or.kr), and the Association of Korean Medicine (AKOM, www.akom.org). Other information about the smoking cessation programmes was retrieved from the following databases: PubMed, Google, the RISS (Research Information Service System, http://www.riss.kr), the KISS (Korean Studies Information Service, http://kiss.kstudy.com), the NDSL (National Digital Science Library, http:// www.ndsl.kr), and the OASIS (Korean Medicine Information System, https://oasis.kiom.re.kr). Additionally, a summary of and detailed information about the smoking cessation programmes or projects of TKM were investigated through the following smoking cessation information database systems and treatment guidelines: the TKM Public Service Report [12], the Public Health Information System (PHIS) [13], the Ministry of Gender Equality and Family (MOGEF) internal data [14], and the Guideline on Health Insurance supported smoking cessation treatment [15]. The first three reports were non-public, private reports and the last guideline can be found at www.nosmokeguide.or.kr. Additional data were obtained by directly contacting related institutions.

The data were searched for with the following keyword combinations on March 10th, 2016: "smok*", "tobacco", "nicotine", and "cessation", "stop", "free", "control", "manage", "treatment" and "program", project" and "Korean medicine", "integrative medicine", "complementary and alternative medicine", "acupuncture", "ear-acupuncture", "herbal medicine", "herb", "aromatherapy, "aroma”, "moxibustion". All smoking cessation programs, projects, or services using TKM were included. There were no restrictions on language, implementation site and year.

\section{Data analysis}

Two researchers searched and selected the studies and reports independently. When a disagreement occurred, a third researcher resolved. The data were extracted into the predefined data extraction form. General information about each project, such as the programme or project title, government agency, start year, programme conducting site, targeted population, budget, number of participants, and detailed contents of each programme were descriptively presented.

\section{Results}

Smoking cessation programmes using TKM can be categorized into 3 groups: (1) public health centre smoking cessation programmes, (2) Ministry of Gender Equality \& Family smoking cessation programmes focused on the teenagers, and (3) National Health Insurance Service smoking cessation treatment projects. The summaries of these 3 programmes are shown in Table 1. Detailed information regarding each programme is described in Table 2. 
Table 1 Summary on TKM smoking cessation programmes in South Korea

\begin{tabular}{|c|c|c|c|c|}
\hline $\begin{array}{l}\text { TKM smoking } \\
\text { cessation programme }\end{array}$ & PHC-SCP & \multicolumn{2}{|l|}{ MOGEF-SCP } & NHIS-SCP \\
\hline Targeted population & Teenagers, Adults & \multicolumn{2}{|l|}{ Teenagers } & Anyone \\
\hline Related agency & $\mathrm{PHC}, \mathrm{MW}$ & \multicolumn{2}{|l|}{ MOGEF, MW } & NHIS, MW \\
\hline Start year & 2001 & \multicolumn{2}{|l|}{2003} & 2015 \\
\hline Subtype & NA & $\begin{array}{l}\text { Designation } \\
\text { clinic system }\end{array}$ & $\begin{array}{l}\text { Designation } \\
\text { doctor system }\end{array}$ & NA \\
\hline Conducting site & PHCs, Schools, Companies & TKM clinics & Schools & TKM clinics \\
\hline Medical cost & No medical cost for the patients & \multicolumn{2}{|c|}{ No medical cost for the patients } & $\begin{array}{l}\text { Supports } 80 \% \text { of medical costs } \\
\text { (not including TKM treatments) }\end{array}$ \\
\hline Budget (per year) & NR & \multicolumn{2}{|l|}{ USD $50,000^{\mathrm{a}}$} & USD $87,000,000^{\mathrm{a}}$ \\
\hline Number of participating institutions & $\begin{array}{l}9 \text { PHCs (2001) } \\
\rightarrow 137 \text { PHCs (2003) } \\
\rightarrow 35 \text { PHCs (2007) } \\
\rightarrow 34 \text { PHCs (2013) }\end{array}$ & $\begin{array}{l}908 \text { TKM clinics } \\
\text { (in 2014) }\end{array}$ & $\begin{array}{l}84 \text { TKM doctors } \\
\text { (in 2014) }\end{array}$ & $\begin{array}{l}\text { 1,270 TKM clinics } \\
\text { (in March 2016) }\end{array}$ \\
\hline Number of participants & $\begin{array}{l}238,951 \\
(2005-2014)\end{array}$ & \multicolumn{2}{|l|}{$\begin{array}{l}96,003 \\
(2003-2014)\end{array}$} & $\begin{array}{l}\text { 162,010 } \\
\text { (2015-present) }\end{array}$ \\
\hline Evaluation index & $\begin{array}{l}\text { Satisfaction, } \\
\text { Cessation success rate }\end{array}$ & \multicolumn{2}{|c|}{ Cessation success rate } & Cessation success rate \\
\hline Characteristics & $\begin{array}{l}\text { Oldest PHC-based programme } \\
\text { typically integrated }\end{array}$ & \multicolumn{2}{|c|}{$\begin{array}{l}\text { Free programme for teenagers } \\
\text { (a vulnerable group) }\end{array}$} & $\begin{array}{l}\text { Clinic-based programme } \\
\text { supported by the health } \\
\text { insurance project fund }\end{array}$ \\
\hline
\end{tabular}

a USD United States dollar. It was based on the annual average exchange rate in 2015 from the Korea Exchange Bank

PHC-SCP Public health centre smoking cessation program, MOGEF-SCP Ministry of Gender Equality \& Family smoking cessation program, NHIS-SCP National Health Insurance Service smoking cessation treatment project, TKM Tradition Korean Medicine, MW Ministry of Health \& Welfare, NHIS National Health Insurance Service,

PHC Public Health Centre, MOGEF Ministry of Gender Equality \& Family, NA not applicable, NR not reported

\section{1st major smoking cessation program: Public Health Centre Smoking Cessation Programme (PHC-SCP)}

PHC-SCP is defined as a 'TKM smoking cessation class' in Table 1. It can be divided into 3 phases. In 2001, the 1st phase programme started as a pilot in 9 public health centres. PHC-SCP mainly performed acupuncture treatments. The programme was targeted at both adults and teenagers. The scale of this programme had expanded, and 137 public health centres participated in PHC-SCP in 2003 (Table 1).

In 2004, a 2nd phase PHC-SCP, which provided education as well as acupuncture, was introduced. This programme involved perceiving the harms of smoking and reaching complete smoking cessation. The programme consisted of 3 sections: training for smoking cessation, acupuncture treatment, and observing the changes in smoking patterns. Table 2 presents the specific interventions. It had been TKM-Hub public health centre period from 2005 to 2012. Although the contents of the PHCSCP were slightly different for each local public health centre, the basic structure originated from the 2004 programme. Managing withdrawal symptoms and counselling could be optionally conducted in some public health centres.

In 2013, a 3rd phase community-based, integrated health promotion programme began in South Korea [16]. As a result, non-smoking programmes using TKM alone have stopped and most have been replaced with those that are associated with non-smoking clinics in public health centres. The addition of TKM to existing non-smoking clinic programmes was expected to be synergistic as each department could be involved in the programme. For example, patients could receive advice from counsellors, acupuncture from the Korean medicine clinics and both an NRT prescription and urine test from the internal medicine clinics.

2nd major smoking cessation program: Ministry of Gender Equality \& Family Smoking Cessation Programme (MOGEF-SCP)

The MOGEF-SCP is defined as an 'Ear acupuncture programme for teenagers', and was organised by the MOGEF with the MW in 2003. The purpose of this programme is to help teenagers control their tobacco habits and to reduce the smoking rate in the community at no cost for the participants. Table 1 presents basic information about this programme.

The MOGEF-SCP is divided into two subtypes, a 'designation clinic system' and a 'designation doctor system' (Table 1). The designation clinic system assigns particular TKM clinics as ear acupuncture treatment institutions, and they offer ear acupuncture to smoking teenagers. The 'designation doctor system' involves TKM doctors who visit schools and provide ear acupuncture. The designation 
Table 2 Details of programmes using TKM for smoking cessation

\begin{tabular}{|c|c|c|c|c|c|}
\hline \multicolumn{2}{|l|}{ Interventions } & \multirow{2}{*}{$\begin{array}{l}\text { Program } \\
\text { Needle type }\end{array}$} & \multirow{2}{*}{$\begin{array}{l}\text { PHC-SCP } \\
\text { Intradermal needle }\end{array}$} & \multirow{2}{*}{$\begin{array}{l}\text { MOGEF-SCP } \\
\text { Intradermal needle }\end{array}$} & \multirow{2}{*}{$\begin{array}{l}\text { NHIS-SCP } \\
\text { Intradermal needle }\end{array}$} \\
\hline Korean & Ear & & & & \\
\hline & & Acupoints & $\begin{array}{l}\text { Lung, Shinmun, Endocrine, Pharynx } \\
\& \text { Larynx and Inner nose }\end{array}$ & $\begin{array}{l}\text { Lung, Shinmun, Endocrine, } \\
\text { Pharynx \& Larynx and Inner nose }\end{array}$ & $\begin{array}{l}\text { Lung, Shinmun, Endocrine, } \\
\text { Pharynx \& Larynx and Inner nose }\end{array}$ \\
\hline & & Duration & $3-4 \mathrm{~h}$ & $3-4 h$ & $3-4 h$ \\
\hline & Manual & Needle type & NA & NA & Basic needle \\
\hline & & Acupoints & NA & NA & $\begin{array}{l}\text { HT7, ST36, } \\
\text { LI4, LU7, LU6 }\end{array}$ \\
\hline & & Duration & NA & NA & $15-20 \min$ \\
\hline & Herbal medici & & NA & $\begin{array}{l}\text { Non-smoking pill } \\
\text { (Optionally) }\end{array}$ & $\begin{array}{l}\text { - Anxiety: Modified Xiaoyao } \\
\text { Powder } \\
\text { Cough: Shensuyin } \\
\text { - Phlegm: Banxia-Houpo-tang or } \\
\text { Erchen-tang } \\
\text { (Optionally) }\end{array}$ \\
\hline \multirow[t]{6}{*}{$\begin{array}{l}\text { Adjuvant } \\
\text { therapy }\end{array}$} & NRTs & & $\begin{array}{l}\text {-Nicotine patch } \\
\text {-Nicotine gum }\end{array}$ & NA & $\begin{array}{l}\text { Nicotine patch } \\
\text { - Nicotine gum }\end{array}$ \\
\hline & Other tools & & $\begin{array}{l}\text { Non-smoking doll } \\
\text { (showing harms of cigarettes) }\end{array}$ & Self-writing handbook & NA \\
\hline & Consultation & Consultant & Health care provider & TKM doctor & TKM doctor \\
\hline & & Type & $5 \mathrm{~A}$ type counselling ${ }^{\mathrm{a}}$ & $\begin{array}{l}\text { 5A type counselling } \\
\text { (Dependent on doctor) }\end{array}$ & $\begin{array}{l}5 \mathrm{~A} \text { type counselling (Dependent } \\
\text { on doctor) }\end{array}$ \\
\hline & & Duration & $10-15 \mathrm{~min}$ & $5-10 \mathrm{~min}$ & $5-10 \mathrm{~min}$ \\
\hline & Education pro & gram & $\begin{array}{l}\text { Watching a video on harms of } \\
\text { smoking } \\
\text { Smoking detox experiment } \\
\text { (goldfish experiment with } \\
\text { cigarettes) }\end{array}$ & $\begin{array}{l}\text { Watching a video on harms of } \\
\text { smoking }\end{array}$ & NA \\
\hline \multirow[t]{6}{*}{$\begin{array}{l}\text { Basic } \\
\text { information }\end{array}$} & Medical cost & $\begin{array}{l}\text { Patient } \\
\text { cost sharing }\end{array}$ & Free & Free & $20 \%$ \\
\hline & & $\begin{array}{l}\text { Government } \\
\text { supports }\end{array}$ & $100 \%$ support & $100 \%$ support & $80 \%$ support \\
\hline & Treatment per & riod & $\begin{array}{l}\text { Dependent on each PHC } \\
\text { (Typically } 4 \text { weeks) }\end{array}$ & 3 weeks & $\begin{array}{l}8 \text { or } 12 \text { weeks } \\
\text { (Dependent on patient's choice) }\end{array}$ \\
\hline & Treatment frec & quency & $\begin{array}{l}\text { Dependent on each PHC } \\
\text { (Typically twice a week) }\end{array}$ & Twice a week & Dependent on each clinic \\
\hline & Primary outco & me & Exhaled CO & $\begin{array}{l}\text { Self-reported cessation success } \\
\text { rate }\end{array}$ & $\begin{array}{l}\text { Self-reported cessation success } \\
\text { rate }\end{array}$ \\
\hline & Characteristics & & $\begin{array}{l}\text { Utilises a variety of methods for } \\
\text { cessation }\end{array}$ & $\begin{array}{l}\text { Mainly acupuncture and } \\
\text { additional education }\end{array}$ & $\begin{array}{l}\text { Similar to the course of } \\
\text { treatment in TKM clinics }\end{array}$ \\
\hline
\end{tabular}

${ }^{a} 5$ A type counselling: 5A means 'Ask', 'Assess', 'Advise', 'Assist', and 'Arrange'

PHC-SCP Public health centre smoking cessation program, MOGEF-SCP Ministry of Gender Equality \& Family smoking cessation program, NHIS-SCP National Health Insurance Service smoking cessation treatment project, TKM Traditional Korean Medicine, NA not applicable, NRT Nicotine Replacement Treatment

doctor system began in 2010. One middle school and one high school are selected by each local organization to participate in the programme. Ear acupuncture is used as main the intervention twice a week for 3 weeks (Table 2). Health counselling and education are also carried out, and a non-smoking pill, which is a TKM smoking cessation aid, is offered as needed. The herbal compositions of the non-smoking pill are Pueraria lobate Ohwi, Glycyrrhiza uralensis, Zingiber officinale, Platycodon grandiflorum, Inula helenium, Mentha piperita, Adenophora triphylla, Amomum xanthioides, Rhynchosia nulubilis, Dryobalanops aromatica, Cinnamomum cassia, Citrus unshiu, and Fritillaria ussuriensis [17].

3rd major smoking cessation program: National Health Insurance Service Smoking Cessation treatment Project (NHIS-SCP)

The NHIS-SCP is a smoking cessation treatment services supported by the NHIS and the MW that started in 2015. The NHIS-SCP provides smoking cessation treatment to patients who want to participate up to twice a year (Table 1). 
Patients visit medical institutions, such as hospitals, clinics, or public health centres, which are registered to offer smoking cessation treatment. The total treatment period is 8 or 12 weeks, and patients are provided with counselling up to 6 times and drugs or nicotine replacement therapies (NRTs) for tobacco control. A total $80 \%$ of a patient's medical expenses are covered, and the expenses for varenicline, bupropion, and NRTs (i.e., nicotine patch, gum, and tablet) are currently covered by a pilot project budget of the NHIS (Table 2).

Table 2 shows the interventions that TKM doctors use in the process of cessation treatment. Medical consultation is included, whereas, acupuncture is not currently used in the NHIS-SCP. However, the TKM doctors can prescribe acupuncture or herbal medicines to relieve withdrawal symptoms if the patients pay for the medical expenses with their own money $[18,19]$. Acupuncture for smoking cessation is provided in many TKM clinics, although it is not yet covered by health insurance. There are 1,270 registered smoking cessation treatment TKM clinics and 204 clinics carry out treatment as of March 2016 (Table 1) [20].

\section{Discussion}

This study described smoking cessation programmes that use TKM interventions in South Korea, and the study results provide basic information for planning future smoking cessation programmes to contribute increasing smoking cessation rates and finally promoting health. In conventional western medicine, there are smoking cessation treatment guidelines for primary care physicians that were developed by the Korean Academy of Family Medicine [21]. The guidelines recommend following doctors' advice, individual or group behavioural counselling, selfhelp interventions, attending smoking cessation clinics, and medicinal treatments, such as bupropion, nortriptyline, and NRT.

In China, a non-smoking clinic was established in 2007 at the Acupuncture and Moxibustion Hospital, Academy of Chinese Medical Sciences, and the patients were treated with acupuncture, massages, and herbal patches [22]. Traditional Chinese medicine (TCM) is relatively well used in cessation treatment; however, there are no national cessation programmes using TCM that are led by the government.

The PHC-SCP, also known as the TKM smoking cessation class, was included in five health promotion programmes. The budget for all 5 of the Health Promotion Programmes using Tradition Korean Medicine (HaPPTKM) was USD 300,000 per public health centre; however, it is unclear how much was used for the PHC-SCP (Table 1). Additionally, the details of the PHC-SCP are slightly different for each public health centre. However, the PHC-SCP is integrated with western medicine programmes, and this is a strong advantage that the other programmes do not provide.

The implementation of the MOGEF-SCP is relatively easy due to the cooperation of schools, which provide good conditions for not only performing treatments but also providing education. Acupuncture is more appropriate than NRT for teenagers because NRT is not recommended for them [5]. Non-smoking pill is used in some TKM clinics optionally, according to the judgment of TKM doctors. Meanwhile, a herbal nicotine patch was developed and has been sold as general medicine in China [23].

The NHIS-SCP enhanced the accessibility to tobacco control therapy by providing medical care in clinics to anyone. Accordingly, the number of participants has overwhelmingly increased, and the budget for full support of medical costs was limited. However, this programme is still in its stages and TKM interventions, such as acupuncture and herbal medicines, are not yet covered by insurance. In Japan, cessation treatments have been covered by health insurance since 2006; however, traditional medicine is not included in the cessation treatment programmes [24].

The treatments are provided according to the guidelines for TKM cessation treatment in South Korea. According to Park's study [25], ear acupuncture was the most frequently used TKM intervention for cessation treatment. The developed guidelines are the 'Guideline on Acupuncture Treatment and Counselling for Smoking Cessation' [26], developed by the Association of Korean Medicine (AKOM), and the 'Guideline on Smoking Cessation Treatment for Health Care Providers' [27], developed by the Ministry of Health and Welfare (MW) and the National Health Insurance Service (NHIS).

Currently, the main TKM intervention used in the smoking cessation programmes is acupuncture [25]. There are many clinical trials using ear- or body-acupuncture as an intervention in several countries [28]. As a result of the ear acupuncture treatments provided through the MOGEF-SCP, 102 of 472 (22.5\%) high school students who had more than 5 ear acupuncture treatments succeeded in complete smoking cessation, and 360 (75.6\%) showed smoking cessation or significant smoking reduction [29]. Herbal medicines were used to help relieve withdrawal symptoms, including anxiety, increased appetite, and phlegm.

As the study of the national lead T\&CM in smoking cessation programmes was few, our study results provide details about the interventions used in TKM smoking cessation programmes in South Korea (Table 2). This is also differentiation of this study because $T \& C M$ is not included in national lead cessation programme in other countries. On the basis of our study, information can be utilised when planning smoking cessation treatments with $\mathrm{T} \& \mathrm{CM}$ in other strategies or countries. Furthermore, the 
study results suggest future research plans for tobacco control studies.

However, there are limitations of TKM smoking cessation programmes. First of all, cessation rate of each programme was not reported. It is the biggest weakness of this study that comparing endpoints of three programmes cannot be done. Second, TKM is still not highly used in smoking cessation treatment. This should be followed by government support. TKM interventions are not supported in the NHIS-SCP and the medical cost is relatively expensive compared with that of conventional western medicines. Third, the evaluation of TKM programmes is insufficient. Quantitative assessments, such as urine tests and pulmonary function tests, and qualitative assessment should be utilised to properly evaluate the programmes. In last, since the lack of reporting form and system, some information such as the number of participating institutions, and budgets were unable to report. The reporting system should be established to keep sustainable programmes. Fourth, a standard guideline for TKM smoking cessation treatment based on welldesigned trial results is needed to support its efficacy and safety. Finally, various TKM interventions, such as herbal medicines and moxibustion, should be developed to increase smoking success rate.

\section{Conclusions}

In South Korea, traditional medicine has been used for smoking cessation treatment mainly in primary medical institutions. This study summarised Korean smoking cessation programmes that use TKM, and it is the first article to provide related information and a brief history of each programme. This will be a reference for other strategies that are to apply traditional medicine to their smoking cessation programmes.

\section{Additional file}

Additional file 1: Guideline on Health Insurance supported smoking cessation treatment. (PDF $3560 \mathrm{~KB}$ )

\section{Abbreviations}

AKOM: Association of Korean Medicine; FCTC: Framework Convention on Tobacco Control; MOGEF: Ministry of Gender Equality and Family; MOGEFSCP: Ministry of Gender Equality and Family smoking cessation program; MW: Ministry of Health \& Welfare; NHIS: National Health Insurance Service; NHIS-SCP: National Health Insurance Service smoking cessation treatment project; NRT: Nicotine replacement therapy; PHC-SCP: Public health centre smoking cessation program; PHIS: Public Health Information System; T\&CM: Traditional and alternative medicine; TCM: Traditional Chinese medicine; TKM: Traditional Korean medicine; WHO: World Health Organization

\section{Acknowledgements}

This research was supported by the Daejeon University Research Grants (2016).

\section{Funding}

None.

\section{Availability of data and material}

This study does not contain any individual person's data.

The data sources used in this study are 1) the TKM Public Service Report, 2) the Public Health Information System (PHIS), 3) the Ministry of Gender Equality \& Family (MOGEF) internal data, and 4) the Guideline on Health Insurance supported smoking cessation treatment. Among them, the TKM Public Service Report, the Public Health Information System (PHIS), and the Ministry of Gender Equality \& Family (MOGEF) are closed internal data of Ministry of Health \& Welfare (MW) and the Ministry of Gender Equality \& Family (MOGEF). The website of PHIS (http://intra.mw.go.kr:7001) is only accessible with public health centers and government related institutions. The Guideline on Health Insurance supported smoking cessation treatment is open material (Additional file 1).

\section{Authors' contributions \\ SJ and YLP drafted the manuscript. KHK, EKL, and SHS searched and extracted the data. JAL and SJP organised and conducted the study. YCS and SKG supervised the study. All authors read and approved the final manuscript.}

\section{Competing interest}

The authors declare that they have no competing interests.

\section{Consent for publication}

As this study is not a clinical trial, consent for publication was not needed.

\section{Ethical approval and consent to participate}

As this study is not a clinical trial, the ethical approval and consent was not needed.

\section{Author details}

${ }^{1}$ Department of Preventive Medicine, College of Korean Medicine, Kyung Hee University, 26 Kyungheedae-ro, Dongdaemun-gu, Seoul 02447, Republic of Korea. ${ }^{2}$ KM Fundamental Research Division, Korea Institute of Oriental Medicine, 1672 Yuseongdae-ro, Yuseong-gu, Daejeon 34054, Republic of Korea. ${ }^{3}$ Department of Korean Internal Medicine, College of Korean Medicine, Sang-ji University Korean medicine Hospital, 80 Sangjidae-gil, Wonju 26338, Republic of Korea. ${ }^{4}$ Department of Preventive Medicine, College of Korean Medicine, Daejeon University, 62 Daehak-ro, Daejeon 34520, Republic of Korea.

Received: 13 August 2016 Accepted: 16 November 2016

Published online: 01 December 2016

\section{References}

1. WHO. Third WHO Report on the Global Tobacco Epidemic. Geneva: WHO; 2012.

2. WHO. Prevalence of tobacco use [Internet] Available from: http://www.who. int/gho/tobacco/use/en/. 2015.

3. WHO. WHO Framework Convention on Tobacco Control. 2005.

4. Cahill K, Stevens S, Perera R, Lancaster T. Pharmacological interventions for smoking cessation: an overview and networkmeta-analysis. Cochrane Database of Systematic Reviews 2013(5):DOl: 10.1002/14651858. CD14009329.pub14651852.

5. Stead LF, Perera R, Bullen C, Mant D, Hartmann-Boyce J, Cahill K, et al. Nicotine replacement therapy for smoking cessation. Cochrane Database of Systematic Reviews 2012(11):DOI: 10.1002/14651858.CD14000146. pub14651854.

6. Fiore MC, Jaén CR, Baker TB, Bailey WC, Benowitz NL, Curry SJ, et al. Treating Tobacco Use and Dependence: 2008 Update.Clinical Practice Guideline. Rockville, MD: U.S: Department of Health and Human Services. Public Health Service. 2008.

7. Dierker LC, Donny E, Tiffany S, Colby SM, Perrine N, Clayton RR. The association between cigarette smoking and DSM-IV nicotine dependence among first year college students. Drug Alcohol Depend. 2007;86(2-3):106-14.

8. Kitikannakorna N, Chaiyakunapruk N, Nimpitakpong P, Dilokthornsakul P, Meepoo E, Kerdpeng W. An overview of the evidences of herbals for smoking cessation. Complement Ther Med. 2013;21:557-64.

9. Chae Y, Kang OS, Lee HJ, Kim SY, Lee H, Park HK, et al. Effect of acupuncture on selective attention for smoking-related visual cues in smokers. Neurol Res. 2010;32(Supplement 1):27-30. 
10. Chae Y, Park HJ, Kang OS, Lee HJ, Kim SY, Yin CS, et al. Acupuncture attenuates autonomic responses to smoking-related visual cues. Complement Ther Med. 2011;19(Supplement 1):S1-7.

11. Ministry of Health and Welfare. Health Plan 2020. 3rd ed. 2011.

12. Traditional Korean Medicine Public Health Assessment Team. Traditional Korean Medicine Public Service Report. Ministry of Health \& Welfare Divison of Traditional Korean Medicine Policy; 2010.

13. Korean Health Promotion Foundation. Public Health Information System [Internet] Available from: http://intra.mw.go.kr:7001. Accessed 30 July 2016

14. Ministry of Gender Equality and Family. Ministry of Gender Equality and Family internal data. 2014.

15. Ministry of Health \& Welfare, National Health Insurance Service. Guideline on Health Insurace supported smoking cessation treatment. 2015.

16. Kim KH, Choi J, Go HY, Lee JA, Lee MS, Park S, et al. Health promotion programme using Traditional Korean Medicine (HaPP-TKM): An overview. Eur J Intern Med. 2015;7(6):628-33.

17. The Society of Korean Medicine Pain Control \& Delivery System [Internet] 2015. Availabel from: http://www.kopadds.org. Accessed 30 July 2016

18. Medical Service Act Article 1-3 [Internet] Available from: http://elaw.klri.re.kr/ kor_service/lawView.do?hseq=35629\&lang=ENG. Accessed 30 July 2016.

19. Korean Standard Statistical Classification [Internet]. Available from: https:// kssc.kostat.go.kr:8443/ksscNew_web/ekssc/main/main.do\#. Accessed 30 July 2016.

20. National Health Insurance Service [Internet]. 2016. Available from: http:// www.nhis.or.kr. Accessed 30 July 2016.

21. Noh HM, Paek YJ, Lee CM. Smoking cessation guidelines in the primary care setting. Korean J Fam Pract. 2013;3:153-62.

22. Beijing's First Use of Chinese Medicine to Quit Smoking to Prevent Lung Cancer in Outpatient Clinic [Press Release]. 2007. Available from: http:// www.xinhuanet.com/chinanews/2007-04/16/content_9801533.htm. Accessed July 302016.

23. TobaccoChina [Internet] Available from: http://www.tobaccochina.com. Accessed July 302016.

24. Japanese Cardiology Society, Japanese Lung Cancer Society Japanese Cancer Society. Japanese clinical practice guideline for smoking cessation 6th Edition. 2014.

25. Park YL, Jang S, Sung HK, Kweon SU, Sung JW, Yang J, et al. A Systematic Review on clinical studies of Korean medicine for smoking cessation Focusing on study design. J Soc Preventive Korean Med. 2015:19(3):115-29.

26. Association of Korean Medicine. Guideline on acupuncture treatment and counseling for smoking cessation. 2010.

27. Ministry of Health \& Welfare, National Health Insurance Service. Guideline on smoking cessation treatment for health care providers. 2015.

28. Di YM, May BH, Zhang AL, Zhou IW, Worsnop C, Xue CCL. A meta-analysis of ear-acupuncture, ear-acupressure and auriculotherapy for cigarette smoking cessation. Drug Alcohol Depend. 2014;142:14-23.

29. Research Institute of Korean Medicine Policy. Research Institute of Korean Medicine Policy Survey Results. 2014.

\section{Submit your next manuscript to BioMed Central and we will help you at every step:}

- We accept pre-submission inquiries

- Our selector tool helps you to find the most relevant journal

- We provide round the clock customer support

- Convenient online submission

- Thorough peer review

- Inclusion in PubMed and all major indexing services

- Maximum visibility for your research

Submit your manuscript at www.biomedcentral.com/submit 